\title{
ADOPCIÓN HOMOPARENTAL Y SU INCIDENCIA EN EL INTE- RÉS SUPERIOR DEL NIÑO
}

\author{
Mayra Evelyna Bajales*
}

\section{Introito}

La organización de la familia ha sido ordinariamente sobre la base del matrimonio heterosexual, considerado hasta no hace mucho como el ideal ético y jurídico a seguir en orden a la protección de intereses superiores que atañen a la comunidad de la que forma parte. Sin embargo, la profunda evolución de las costumbres a partir de la segunda mitad del siglo XX dio lugar a que se considere, frente al estereotipo clásico de familia, a otros modelos que se producen por actos voluntarios o aún de hechos fortuitos, generando las nuevas formas de familia entre las que se encuentra la familia homosexual.

Este trabajo analizará las aristas de la adopción homoparental u homoafectiva, ${ }^{1}$ desde una mirada interdisciplinaria, partiendo desde el punto de vista jurídico (el cual no se puede dejar de abordar, más aún desde la sanción de la Ley $\mathrm{N}^{\circ}$ 26618).

Puesto que el fin de la adopción no es tanto dar un hijo a unos padres, que no lo tienen, como dar unos padres idóneos a un niño que carece de ellos, ¿es conveniente o no para un niño, tener por padres a una pareja homosexual? Esta pregunta central y otras cuestiones relacionadas serán materia de análisis, sin olvidar que el eje central en materia de niñez y adolescencia no puede alejarse del principio rector del interés superior del niño, establecido por la Convención de los Derechos del Niño (en adelante, CDN) y la Ley No 26061 (Protección Integral de los Niños, Niñas y Adolescentes).

* Maestrando en Derecho de Familia, Niñez y Adolescencia de la Facultad de Derecho, UNNE. Profesora libre en la cátedra "B" de Derecho Administrativo de la Facultad de Derecho, UNNE. Becaria de investigación, categoría perfeccionamiento tipo A, SGCyT de la UNNE.

${ }^{1}$ Término acuñado por varios autores más “progresistas” del derecho de familia brasilero que pertenecen y dirigen actualmente el instituto brasilero de derecho de familia (ibdfam). Esta línea autoral ubica este tipo de lazos dentro de las llamadas relaciones "socioafectivas". 
El instituto de la adopción -como procedimiento legal y legítimo avalado por la legislación internacional- tiene por finalidad la protección integral de niños, niñas y adolescentes que no dispongan de una organización familiar capaz de proporcionársela. Entendiendo esto como una institución orientada al derecho de los niños, niñas y adolescentes a tener una familia que pueda satisfacer todos sus requerimientos y necesidades y NO a proporcionar a los adultos (sin distinción de la orientación sexual que ostenten) a ser padres. El problema de fondo reside en que la adopción no es una institución creada para llenar vacíos o para satisfacer la aspiración de una pareja, por respetable y digno que sea ese sentimiento. La adopción está instituida para servir al interés del menor que la familia quiere incorporar a su seno.

Tampoco puede ignorarse que la existencia de esta nueva clase de familia está lejos de gozar de una plena aceptación social o de suscitar un mínimo consenso en la comunidad, aún cuando desde lo jurídico se pregonen los principios de igualdad y no discriminación.

\section{Cuestiones atinentes a la Ley $N^{\circ} 26618$}

Según Lloveras, Orlandi y Faraoni, ${ }^{2}$ la recepción por el derecho argentino del matrimonio entre personas de diferente y del mismo sexo por esta ley, satisface los derechos fundamentales de las personas, dando fin a algunas discriminaciones que lentamente se van superando. Esta ley, denominada comúnmente de "matrimonio igualitario", modifica sustancialmente algunos artículos del Código Civil, en lo referente al matrimonio y la adopción. Este último es uno de los temas más sensibles de dicha ley pues la tensión que genera la adopción en general por una o dos personas del mismo sexo pasa, en definitiva, por indagar si afecta, contraría o viola el principio rector en materia de infancia, el "interés superior del niño", o si, por el contrario, este principio solo serviría de excusa o pantalla detrás de la cual se esconde un acto más de abierta discriminación hacia las parejas del mismo sexo.

Este conflicto acerca de la aceptación o negativa de la adopción sobre la base de la orientación sexual de los adoptantes involucra cuestiones y saberes que no son exclusivos del campo jurídico sino también de otras disciplinas; prin-

${ }^{2}$ LLoveras, Nora; Orlandi, Olga y Faraoni, Fabián (2010). “El matrimonio civil argentino. Análisis de la Ley 26618/2010”, Nuevo Enfoque Jurídico, Córdoba, pág. 29. 
cipalmente de la psicología, cuando alude a los efectos psico-sociales en los niños de ser criados por personas del mismo sexo.

En cuanto al instituto de la adopción, y toda vez que ya no se exige para contraer matrimonio la diversidad de sexos, las parejas casadas pueden adoptar niños en forma conjunta, sin distinción. Ya ha quedado claro en el debate social y también parlamentario, que hasta hoy no regía ninguna ley que exigiera determinada orientación sexual para ser adoptante. Tampoco podría haber existido dicho requisito, por veda constitucional. Esta posibilidad que se abre ahora, para las parejas del mismo sexo, de ser adoptantes en forma conjunta y en tanto conformen un matrimonio, repara una situación injusta que sufrían hasta ahora los niños adoptados que, pese a ser buscados y criados en una pareja homosexual, figuraban adoptados por solo uno de los integrantes de esa pareja, precisamente debido a la imposibilidad de estos de contraer matrimonio. Esta situación tenía efectos en la vida cotidiana y en disfavor de los menores: ante una separación solo quedaba obligado a prestar alimentos quien figuraba como adoptante; los niños podían quedar sin régimen de visitas del otro integrante de la pareja pese a que este lo había criado, a veces, por años; solo podían gozar de los beneficios sociales por parte del adoptante pudiendo quedar sin protección si este no tenía empleo; solo podían heredar al registrado como adoptante y ante el fallecimiento de este, en más de una situación se los ha considerado en estado de orfandad, sin reconocimiento de vínculo alguno con quien no figuraba como adoptante. Estos ejemplos demuestran que esos niños sufrían por reflejo la discriminación que la ley realizaba respecto de sus padres debidos, precisamente, a la orientación sexual de estos, circunstancia claramente violatoria del art. 2 CDN.

En el afán de dar respuestas a la adopción por personas del mismo sexo, Gil Domínguez ${ }^{3}$ estima que si queremos pensarla de manera amplia y respetuosa, debemos movernos más allá de las dicotomías naturaleza / cultura; innato / adquirido; gestación / crianza y madres apropiadas / madres inapropiadas, por nombrar las más frecuentemente utilizadas. Por ello debemos pensar el parentesco como una institución socio-histórica (y por lo tanto cambiante) atravesada por relaciones de poder.

Se entiende que la ley de matrimonio igualitario ha sido un paso importante en reducir el espacio de exclusión que todavía preocupa a muchos sectores en

${ }^{3}$ Citado por LLoveras, Nora; Orlandi, Olga y Faraoni, Fabián en: “El matrimonio civil argentino. Análisis de la Ley 26618/2010”, Nuevo Enfoque Jurídico, Córdoba, pág. 30. 
el derecho argentino, a la vez que genera interrogantes acerca sobre qué dirán los jueces sobre la adopción homoparental, entendiendo que habrá que seguir el proceso de cerca para intentar detectar y combatir lo que podría atestiguar la exclusión de la adopción por pareja del mismo sexo, en particular, cuando se trate de adopción conjunta.

La doctrina mayoritaria entiende que esta nueva regulación devenida de la Ley $\mathrm{N}^{\circ} 26618$, que reforma el derecho de adopción, reconoce materialmente el principio de no discriminación de rango constitucional, tributa abiertamente a favor de la democratización en serio de la sociedad y de la institución familiar, y se ensambla con la constitucional protección del art. 14 bis Const. Nac. y demás pactos internacionales con jerarquía constitucional, marcando un paso histórico aunque resulte insuficiente. ${ }^{4}$ En ese contexto, y en término de "adeptos” y "detractores” de la ley, se puede observar la siguiente clasificación tripartita: 1) personas que están en contra de la Ley $\mathrm{N}^{\circ} 26618$ in totum, es decir, de que se extienda el reconocimiento del derecho a casarse a las personas del mismo sexo, como de todos sus efectos jurídicos; 2) personas que están a favor del matrimonio pero no así de la adopción-posición en la que nos enrolamos, lo que será fundamentado oportunamente en nuestras conclusiones-; y 3) personas que están a favor de ambas figuras, por aplicación del mismo principio constitucional de igualdad y no discriminación, al considerarse que, siendo la orientación sexual una “categoría sospechosa”, recae en el Estado la obligación de brindar fundamentos objetivos y razonables para llevar adelante ciertas y determinadas distinciones. Y que si se carece de esos fundamentos o los argumentos que se otorgan no se encuentran corroborados, la imposición o limitación de ciertos derechos por parte del Estado -en este caso, que la adopción quede reservada a las parejas de diverso sexo- sería una actitud discriminatoria.

\section{Principio del interés superior del niño}

Constituye el eje rector en cualquier decisión que se adopte con miras a garantizar sus derechos. Así lo resolvió la jurisprudencia, recordando que la CDN:

${ }^{4}$ Jáuregui, Jodolfo (2010). “Adopción por parejas del mismo sexo”, pág. 36, ll, sup. esp. “matrimonio civil”, agosto de 2010. 
tiende a la protección e interés superior del niño, y tales principios, en los procesos de filiación, se proyectan con mayor peso ya que pocos derechos humanos pueden ser más dignos de protección que el derecho a ser emplazado en el estado de hijo, a conocer la identidad, a conocer sus raíces, a vivir con la dignidad que otorga el saber de quién se es hijo. ${ }^{5}$

Fue su inclusión en el art. 3 CDN lo que promovió y generó un intenso debate en torno de su contenido y de sus implicancias. Es por ello las múltiples y diversas propuestas sobre los alcances de su aplicación.

La doctrina internacional ha intentado delimitar su concepto y, como punto de partida, en forma coincidente, ha resaltado que es un principio vago, de contenido indeterminado y sujeto a múltiples interpretaciones. Estas características dan muestra de que su aplicación en situaciones concretas no va a conducir necesariamente a un resultado predecible, residiendo el problema en cómo identificar los criterios que habrán de seguirse para evaluar las alternativas que se le ofrecen a la persona que tiene que tomar la decisión cuando pretende actuar en defensa del interés superior del niño. Famá ${ }^{6}$ señala los diferentes planteos metodológicos para su identificación que a nivel doctrinario, legislativo y jurisprudencial se han seguido. Los anglosajones optaron por integrar una lista de situaciones entre las que se incluyen este principio y que servirán a la autoridad encargada de interpretarlo de modo de guía de su decisión. Por el contrario, en los sistemas jurídicos germánicos y latinos suele aparecer tipificado a través de una cláusula general, de manera que la autoridad encargada de aplicarlo tiene la obligación de realizar un juicio de concreción con el fin de situar su contenido. Si bien el resultado de esta concreción encuentra un límite lógico en el propio ordenamiento jurídico del que se extrae la regla, dicho ordenamiento confiere una dimensión significativa a la intervención del órgano judicial como intérprete.

Puede decirse que la determinación del interés superior del niño supone dos etapas diferenciadas: la primera se refiere a lo que podría conceptualizarse como el interés en sentido abstracto, noción marco que se sitúa en la esfera jurídica, obedece a una lógica jurídica y se presta a un enfoque global; la segunda, alude al interés concreto, el cual se encuentra centrado en la esfera prácti-

5 “i., p. a. s/ protección de persona”, C. Nac. Civ., Sala K, 18/02/2000. 
ca, que obedece a una lógica fáctica y se compone de elementos circunstanciales, irreductibles, rebeldes a cualquier sistematización, ya que sistematizarlo significaría desatender las particularidades del caso.

De todos modos, y por más que se pretenda elaborar criterios para circunscribir el alcance de este principio y contribuir a una mayor precisión del concepto, algún grado de indeterminación resulta inevitable.

Considerar al niño como sujeto de derecho es un concepto que remite a su superior interés y necesidad, establecidos y reconocidos en la CDN y, se sustancia en su derecho a vivir en una familia, a educarse, desarrollar su capacidad emocional, afectiva, psicológica y social; a poder desenvolverse protagónicamente en forma autónoma, de acuerdo a cada una de las distintas etapas de su evolución. Esto hace a la consideración del mejor interés de ese niño/niña en condiciones de adaptabilidad, lo que conlleva a atender su imperiosa necesidad de contar con una familia que lo ayude a superar su estado de desamparo. Esa familia que pueda conectarse sinceramente con esa necesidad infantil no puede ser cualquier familia, sino aquella cuyos miembros se encuentren aptos para brindar cobijo, educación, afecto y calor de hogar.

\section{Principios de igualdad y no discriminación}

Para Dworkin, ${ }^{7}$ el principio de igualdad constitucional se integra con el concepto de igual tratamiento y con el de ser tratado como igual. El primero es el derecho a una distribución igual de oportunidad, recursos o cargas. El segundo es el derecho a ser tratado con la misma consideración y respeto que cualquiera.

La contracara o negación del principio de igualdad es la discriminación. Por discriminación se entiende el trato diferencial de los individuos a quienes se considera perteneciente a un grupo social determinado. En nuestro país, si bien las discriminaciones arbitrarias siempre estuvieron implícitamente prohibidas en orden al principio del art. 16 Const. Nac., luego de la reforma de 1994, dicha prohibición ha sido explicitada a través de los instrumentos internacionales de derechos humanos enumerados en el art. 75 inc 22, a saber: la Declaración Universal

${ }^{6}$ Famá, María v. (2011). La filiación. Régimen constitucional, civil y procesal, $2^{\mathrm{a}}$ ed. ampliada y actualizada, Abeledo Perrot, Buenos Aires, pág. 25.

${ }^{7}$ Citado por Famá, María v., ob. cit., pág. 27. 
de Derechos Humanos (art. 7); la Declaración Americana de los Derechos y Deberes del Hombre (art. 2); la Convención Americana sobre Derechos Humanos (art. 24); el Pacto Internacional de Derechos Económicos, Sociales y Culturales (arts. 2 y 10); el Pacto Internacional de Derechos Civiles y Políticos (arts. 2 y 3); la Convención Internacional sobre Eliminación de Todas las Formas de Discriminación Racial; la Convención de Eliminación contra toda Forma de Discriminación contra la Mujer; la Convención contra la Tortura y otros Tratos o Penas Crueles, Inhumanos o Degradantes (art. 1) y la CDN (arts. 2 y 30).

La jurisprudencia de nuestra Corte Suprema ha delineado las siguientes pautas acerca del derecho a la igualdad y el principio de no discriminación: 1) la igualdad exige que se trate del mismo modo a quienes se encuentran en iguales situaciones; 2) por eso implica el derecho a que no establezcan excepciones o privilegios que excluyan a unos de lo que se concede a otros en iguales circunstancias; 3) la regla de igualdad no es absoluta, ni obliga al legislador a no considerar la diversidad de circunstancias, condiciones o diferencias que puedan presentarse a su consideración, lo que la regla estatuye es la obligación de igualar a todas las personas afectadas por una medida, dentro de la categoría o clasificación que les corresponda, evitando distinciones arbitrarias u hostiles; 4) la razonabilidad es la pauta para ponderar la medida de la igualdad; 5) el legislador puede crear categorías, grupos o clasificaciones que irroguen trato diferenciado entre habitantes a condición de que el criterio empleado sea razonable; 6) las desigualdades son inconstitucionales cuando son arbitrarias, hostiles, persecutorias, etc.

\section{Aspectos generales relativos a la adopción homoparental}

Los adultos deseosos de consagrar su parentalidad -según sean los motivos que inducen tal deseo- encuentran en la adopción una alternativa vital que los autoriza a disfrutar de ese derecho humano que conduce a crecer a la vera de aquellos a quienes se consideran y reconocen como hijos. El hijo adoptivo, en tanto deseo de hijo gestado por quienes habrán de adoptarlo es previo a la decisión jurídica que legaliza la entrega de un niño. Según Eva Giberti, ${ }^{8}$ se dife-

${ }^{8}$ Citada por Raices Montero, Jorge y otros en Adopción. La caída de un prejuicio: proyecto de ley nacional de unión civil (2004), Editores del Puerto: Comunidad Homosexual Argentina, Buenos Aires, pág. 85. 
rencia de necesidad de hijo o apetito de hijo. Las parejas heterosexuales atraviesan por el avatar de sustituir la frustración que su capacidad reproductora les imponía y podría conducirlos a la necesidad de un hijo, hasta lograr la construcción de un deseo de hijo. Las parejas homosexuales parten de una concepción de hijo que no incluye la alternativa de engendrarlo, dada la elección sexual de quienes la conforman. Para las parejas que adoptan, fue preciso que ese deseo se conjugase con la oportunidad de ofrecer una familia al niño soñado y deseado, a partir de lo cual la parentalidad podría ejercerse no solo en los hechos concretos y reales sino en la construcción simbólica de un hijo adoptivo. Para lo cual, el soporte y reconocimiento de la ley como garante de los derechos del niño en el momento de la selección de quienes el Estado reconocerá como padres adoptantes, constituye uno de los principios reguladores de los vínculos intrafamiliares que la legalidad funda.

Gil Domínguez, Fama y Herrera ${ }^{9}$ coinciden con Mizrahi al sostener:

es por lo demás inconveniente aferrarse a planteos conceptuales o esquemáticos. En sentido contrario, habrá que partir teniendo en mira la conveniencia concreta del adoptado, de lo que se sigue que el problema tiene que ser materia de consideración específica por el magistrado que tiene a su cargo el análisis de la causa.

Para ello, cada juez deberá contar con el apoyo de un equipo interdisciplinario que facilite y coloque a su alcance las herramientas necesarias para arribar a una solución que resulte la más adecuada en cada caso.

Probablemente uno de los mayores inconvenientes que pueden presentarse resultará de la inserción social del niño adoptado por una pareja homosexual y las probables conductas y actitudes discriminatorias a las que será sometido por sus pares en los diferentes contextos en los cuales el niño desarrolle su existencia -la escuela, el club, el barrio, etc.-. Quizás sea esta una de las más poderosas razones para justificar la preferencia de las uniones heterosexuales frente a las homosexuales a la hora de conceder la adopción de un niño.

${ }^{9}$ Gil Domínguez, Andrés; Famá, María y Herrera, Marisa (2010). Matrimonio igualitario y derecho constitucional de familia, Ediar, Buenos Aires, pág. 133. 


\section{La mirada interdisciplinaria. Voces a favor y en contra}

La tensión que genera la adopción en general por una o dos personas del mismo sexo pasa, en definitiva, por indagar si afecta, contraría o viola el principio rector en materia de infancia, el interés superior del niño, o si, por el contrario, este principio solo serviría de excusa o pantalla detrás de la cual se esconde un acto de abierta discriminación hacia las personas del mismo sexo. Este conflicto acerca de la aceptación o negativa de la adopción sobre la base de la orientación sexual de los adoptantes involucra cuestiones y saberes que no son exclusivos del campo jurídico sino también de otras disciplinas; principalmente de la psicología, cuando alude a los efectos psico-sociales en los niños de ser criados por personas del mismo sexo, y la sociología.

Desde el campo de la psicología, en un informe presentado por la Comunidad Homosexual Argentina (CHA), los psicólogos Jorge Raíces Montero e Isabel Monzón afirman que la homosexualidad de los padres / madres "no tiene por qué definir la misma tendencia en los hijos. Para ellos, las causales por las que una persona se siente atraía por otra del mismo sexo son múltiples y superan la tradicional identificación freudiana”. Asimismo, aseguran que la familia homosexual, incluso puede favorecer a los niños en la medida que les permite: I) Adquirir un mayor aprecio por la diversidad humana: II) Tener una visión más amplia de los roles de género; III) Adquirir una mayor sensación de ser queridos, por las barreras que sus padres debieron superar; IV) Apreciar la división igualitaria del trabajo entre padres / madres, ya que las parejas gays / lesbianas no dividen el cuidado de los niños y tareas del hogar sobre la base de roles de género.

Por lo general, cuando se alude al impacto real de la crianza homoparental en el desarrollo de los niños, se apela a las conclusiones arribadas por la American Academy of Pediatrics (AAP) -institución que nuclear a más de 55.000 pediatras estadounidenses-, que en fecha 04/02/2004 emitió un comunicado en el cual se expresa que "los niños que han nacido o han sido adoptados por un miembro de una pareja de gays / lesbianas merecen la seguridad de tener dos padres legalmente reconocidos”, y en materia de adopción de integración se dice que la AAP "apoya los esfuerzos jurídicos y legislativos que hagan posible la adopción de niños por el segundo padre o co-padre en esas familias”. Ambas afirmaciones se fundan en la siguiente aseveración:

Un cuerpo creciente de literatura científica demuestra que los niños que crecen con uno o dos padres gay y/o lesbiana son iguales en funcionamiento 
cognitivo, social y sexual que los niños cuyos padres son heterosexuales. El desarrollo óptimo de los niños parece ser influido más por la naturaleza de las relaciones e interacciones dentro de la unidad familiar que por la forma estructural particular que toma.

La psicóloga Eva Giberti, al analizar la adopción a la luz de la Ley $\mathrm{N}^{\mathrm{o}}$ 26618, expresa:

La crianza y educación realizada por gays y lesbianas constituye una forma de organización familiar que deberá responder, prioritariamente, al 'interés superior del niño' en tanto y en cuanto, para todos los niños propiciamos un mundo en el que las características de la orientación sexual no impliquen exclusiones.

En autos “L., S.F. c/ A., C.P.”, ${ }^{10}$ la magistrada que resolvió en cuanto a las preferencias sexuales del padre, dijo lo siguiente:

la intolerancia y hostilidad que subyace en la sociedad frente a la elección en la orientación sexual de las personas distinta a la esperada, y que cuando se habla de homosexualidad no se señala una conducta o comportamiento humano, sino que la misma categorización pretende, peligrosamente, hacer de ello un 'diagnóstico'; trasladando, equivocadamente, el eje de la discusión, al hecho de si ser homosexual es bueno o malo, si es beneficioso o perjudicial, cuando en realidad la preocupación del juzgador debe ser, cualquiera sea la orientación sexual de los progenitores, averiguar si éstos reúnen las condiciones necesarias para desempeñar y cumplir el rol parental adecuadamente y tratar de desentrañar qué es lo mejor para el hijo.

Del lado de los que oponen categóricamente, se escucharon voces como la de Medina ${ }^{11}$ quien propuso que las parejas homosexuales no deben estar autorizadas a la adopción y guarda de menores ni al acceso de técnicas de fecunda-

${ }^{10}$ Juzgado de Familia de 4 a nominación, córdoba, 06/08/03.

${ }^{11}$ Citada en Galli Fiant, María (2010), “Reformas legales referidas a la adopción”, en Nuevo régimen legal del matrimonio civil. Ley 26618, Rubinzal Culzoni, Buenos Aires, pág. 149. 
ción asistida. La autora mencionada había tenido una opinión similar, ${ }^{12}$ aunque no tan tajante, al sostener: 1) la preferencia sexual homosexual no es inmoral ni contraria a las buenas costumbres; 2) el interés superior del menor justifica que se prefiera a parejas adoptantes heterosexuales, frente a peticiones de adopción de homosexuales solos; 3) no existiendo interesadas parejas heterosexuales, la preferencia homosexual no puede obstaculizar la adopción; 4) la adopción del hijo del compañero homosexual desnaturaliza el instituto de la adopción, que tiene por fin esencial el crear un parentesco civil similar al que surge de la filiación biológica. Como en la filiación no surge que un niño tenga dos padres o dos madres, nos parece que otorgar derecho a la adopción a la pareja homosexual desnaturalizaría el vínculo filiatorio; 5) el interés de los homosexuales debe conjugarse con el interés de los menores; y 6) la ley brinda medios suficientes para proteger al hijo del compañero homosexual sin desnaturalizar el instituto de la adopción.

Psicoanalistas como Nagay, Socarides, Nicolisi y Lemer alertan sobre los principales riesgos que corren los niños adoptados por parejas homosexuales: trastornos en la identidad sexual, mayor incidencia de comportamientos homosexuales al llegar a la adolescencia, una tendencia significativamente mayor a la confusión y promiscuidad sexual, trastornos de conducta, depresión, comportamientos agresivos, ansiedad, hiperactividad, e insomnio. El niño tiene necesidad del padre y de la madre para identificarse con la persona de su mismo género y para aprender también el respeto, afecto y complementariedad que la persona del otro género le debe proporcionar. El afecto que recibe del padre y de la madre -que es de diversa índole- y la vinculación resultantes de esa relación son imprescindibles para fundar su identidad personal. El niño que solo convive con los «padres» homosexuales adoptivos suele sufrir un déficit en su socialización -al no interiorizar el genuino espíritu de familia que hunde sus raíces en la comunidad entre un hombre y una mujer-, además de un empobrecimiento en su autoestima, por haber sido estructurada de forma incompleta, al relacionarse con figuras parentales de un mismo y único sexo. En consecuencia, en el niño que sea adoptado por homosexuales hay un mayor riesgo de que su identidad pueda resultar maltrecha, incompleta, sectorizada y parcialmente mutilada o estructurada de forma incorrecta y, por consiguiente, insatisfactoria.

${ }^{12}$ Medina, Graciela (2001). Uniones de hecho homosexuales, Rubinzal Culzoni, Santa Fe, pág. 251. 
Mazzinghi (h) ${ }^{13}$ sostiene:

Es conocida la objeción de que la imposibilidad procreadora puede ser suplida con el otorgamiento de la adopción, pero tal expediente debe ser descartado, en cuanto se consumiría en perjuicio del adoptado, al privarlo arbitrariamente del aporte complementario que padre y madre están llamados a efectuar a su educación. (...) El interés superior del niño que consagra la Convención Internacional quedaría así vulnerado.

Mizrahi, ${ }^{14}$ luego de preguntarse acerca de la habilidad de la pareja homosexual para dar nacimiento a una familia, analiza los artículos 16.1 de la Declaración Universal de Derechos Humanos y 17, inc. 2 del Pacto de San José de Costa Rica para afirmar que por estos instrumentos internacionales, con jerarquía constitucional, la respuesta tal vez sería negativa ya que el vínculo homosexual no parece comprendido a los fines de contraer matrimonio y constituir una familia. Coincidiendo con Medina en que el Estado no está obligado a dar igual nivel de protección a las familias homosexuales que a las matrimoniales, esto no empece a la necesidad social de que, por razones de justicia y equidad, se les confiera los derechos patrimoniales, asistenciales y asociativos que correspondan, pues no vislumbra que con la asimilación jurídica al llamado "trato familiar" se afecten intereses de terceros ni el orden público. Estima que importa una decisión de marcada responsabilidad esta suerte de inserción del niño en una situación desigual, imponiéndole sin remedio la pesada carga de tener que confrontarse en un mundo que, por las disimetrías observables, está aún signado por un protagonismo indiscutible de la pareja heterosexual.

Ante estas opiniones antagónicas, algunos autores como Belluscio ${ }^{15}$ mantuvieron una postura más flexible. El autor sostuvo que a pesar de no estar prohibida la adopción por parte de personas solteras o la adopción de homosexuales, cuando la cantidad de aspirantes excede el número de niños adoptables, es legítimo que se prefiera a los matrimonios antes que a las personas solas, $\mathrm{y}$

${ }^{13}$ Mazzinghi, Jorge (h) (2010). Ley de matrimonio entre personas del mismo sexo. A la sombra de Lucrecio, Revista La Ley, suplemento actualidad, 12/10/2010, pág. 1.

${ }^{14}$ Mizrahi, Mauricio (2006). Familia, matrimonio y divorcio, $2^{\mathrm{a}}$ ed. actualizada y ampliada, Astrea, Buenos Aires, pág. 298.

${ }^{15}$ Citado en Jáuregui, Rodolfo, ob. cit., pág. 3. 
a los heterosexuales frente a los homosexuales. Para Belluscio resulta indudable que -como regla- responde al mejor interés del niño que carece de familia el brindarle una familia matrimonial que entregarlo a una persona sola, sea hetero u homosexual; acepta estas soluciones frente a casos particulares, cuando los matrimonios aspirantes sean escasos o no reúnan las condiciones necesarias, o cuando se procure consolidar mediante la adopción un vínculo paterno o materno / filial de hecho. Entiende que negar la posibilidad de adoptar por el solo hecho de ser homosexual resultaría discriminatorio.

\section{Conclusión}

Conforme a los fundamentos esbozados, estamos persuadidos de que nuestro ordenamiento jurídico sustenta y define que el mejor interés del niño o adolescente que se encuentra en condiciones de ser adoptado se satisface proporcionándole una madre y un padre por adopción. Aquel que por las circunstancias de la vida no ha podido permanecer vinculado a sus padres biológicos, merece como alternativa la integración a un medio familiar que respete su derecho a criarse con un padre y con una madre. La pareja de varón y mujer, libres de ideas de superioridad / inferioridad y de imposiciones de roles o funciones estereotipadas relativas a su género (art. 5.a, Convención sobre la Eliminación de todas las Formas de Discriminación contra la Mujer), está llamada al ejercicio compartido de la función parental para la mejor satisfacción de las necesidades de los hijos. Esto no quiere decir que la heterosexualidad constituya garantía de bienestar emocional para los niños y niñas adoptados, ni asegura un desarrollo equilibrado. Dependerá de las condiciones de parentalidad que puedan ejercer y de la concepción de hijo adoptivo que construyen, asumiéndolo como una filiación caracterizada por su capacidad plenificante de los deseos que los hijos reconozcan como propios e identitarios.

Pensamos que la adopción homoparental desnaturaliza el sentido de la adopción tal como está pensado, ya que es de su esencia crear un parentesco civil, más o menos extenso entre adoptante y adoptado, similar al que surge de la filiación biológica, y como de esta y de la naturaleza no surge que un niño tenga dos padres o dos madres, nos parece que otorgar derecho de adopción a la pareja homosexual desnaturalizaría el vínculo filiatorio en virtud del aforismo “adoptio naturam imitatur" (la adopción imita la naturaleza).

Ningún derecho, expectativa o aspiración de los adultos, por legítimos que sean, podrán prevalecer sobre el derecho del niño o adolescente a la hora de 
valorar la conveniencia de su adopción y la apreciación de las cualidades de los postulantes en relación con las necesidades de desarrollo y protección de aquellos. Menos legítimo aún resulta utilizar a los niños como instrumentos de reivindicación de derechos de determinados grupos sociales o convertir a la adopción en una institución funcional a los intereses de algunos sectores. Se trata de encontrar una familia para un niño y no satisfacer intereses de los adultos involucrados.

Los apresuramientos en este terreno tienen el serio riesgo de que las propuestas deriven, tal vez de un modo inconsciente, en el doble discurso: que la mirada esté menos en amparar a la niñez que en satisfacer aspiraciones sectoriales de la comunidad homosexual. La resolución del tema no puede dejar de contemplar los intereses de la humanidad en ascenso; esto es, de los niños de hoy. Y estos intereses, son, sin hesitación, los que han de determinar los límites a los derechos de autonomía, realización personal y privacidad de los adultos.

Más allá de las creencias acerca de que el niño adoptado en el seno de una pareja homosexual carecerá de referencias de comportamientos de ambos sexos y tendrá dificultades en su identificación sexual, lo que más nos causa preocupación es la posibilidad de que ese niño o adolescente pueda ser objeto de repudio en el medio que frecuenta o víctima de burla por parte de colegas y vecinos, lo que podría acarrearle perturbaciones psicológicas o problemas de inserción social. En este momento histórico, el mayor obstáculo en este tipo de adopción está dado por el escaso consenso social que despierta, ocasionando una discriminación que podría resultar muy perjudicial para el adoptado. Este es el alegato más realista e importante: reconocer que nuestra sociedad aún no está preparada para recibir masivamente en su seno esta nueva modalidad familiar. Ya el niño soportará la homosexualidad de sus padres adoptivos como castigo social, a raíz de una difundida y visceral discriminación; ¿ para qué entonces buscar que sufra permitiendo la adopción por una pareja homosexual? Como nuestra sociedad no está preparada, ese sufrimiento será inexorable. La ley puede ejercer una función docente, pero no subvertir tradiciones de un día para el otro. Los niños no deben pagar cualquier precio para el logro de igualaciones entre adultos; cuando se trata de ellos, hay que desplegar suma prudencia y transitar pausado, dando preferencia a sus intereses por encima de la autonomía de voluntad de personas con orientación homosexual.

Sin embargo admitimos la adopción en casos excepcionales, cuando haya una situación paterno-filial consolidada en los hechos, y su destrucción entrañaría 
desarraigo y abandono para el menor. Pero esas excepciones no pueden convertirse en regla, un tema es lo ya consumado y otro lo institucional.

\section{Bibliografía}

Bossert, Gustavo (2011). Unión extraconyugal y matrimonio homosexual, Astrea, Buenos Aires.

Famá, María V. (2011). La Filiación. Régimen Constitucional, Civil y Procesal, $2^{a}$ ed. ampliada y actualizada, Abeledo Perrot, Buenos Aires.

Ferrer, Francisco y otros (2010). Nuevo Régimen Legal del Matrimonio Civil. Ley 26618. Rubinzal Culzoni, Santa Fe.

Gil Domínguez, Andrés; Famá, María y Herrera, Marisa (2010). Matrimonio igualitario y Derecho Constitucional de Familia, Ediar, Buenos Aires.

Gil Domínguez, Andrés (2006). Derecho Constitucional de Familia, T. I, Ediar, Buenos Aires.

Herrera, Marisa (2010). “Adopción y ¿homo-parentalidad u homofobia? Cuando el principio de igualdad manda”, JA 2010-III-1360.

Jáuregui, Rodolfo (2010). “Adopción por parejas del mismo sexo”, LL, Sup. Esp. “Matrimonio Civil”, agosto de 2010.

Lloveras, Nora; Orlandi, Olga y Faraoni, Fabián (2010). “El Matrimonio Civil Argentino. Análisis de la Ley 26618/2010”, Nuevo Enfoque Jurídico, 2010, Córdoba.

Mazzinghi, Jorge (h) (2010). "Ley de matrimonio entre personas del mismo sexo. A la sombra de Lucrecio”, Revista La Ley, Suplemento Actualidad, 12/10/2010.

Medina, Graciela (2001). Uniones de hecho homosexuales, Rubinzal Culzoni, Santa Fe.

Mizrahi, Mauricio (2006). Familia, matrimonio y divorcio, $2^{\mathrm{a}}$ ed. actualizada y ampliada, Astrea, Buenos Aires.

Raices Montero, Jorge y otros (2004). Adopción. La caída de un prejuicio: proyecto de ley nacional de unión civil, Editores del Puerto: Comunidad Homosexual Argentina, Buenos Aires.

Testa, Graciela (2012). “Adopción y parentalidad homosexual ¿impedimento o prejuicio social?”, DJ 26/12/2012. 
Zannoni, Eduardo (2004). “Adopción y homosexualidad, Revista Interdisciplinaria de Doctrina y Jurisprudencia”. Derecho de Familia, N 37, LexisNexis, Buenos Aires. 